\title{
Safety and Yield of Exhaled Breath Condensate Analysis in Acutely Ill, Mechanically Ventilated Infants with RSV Bronchiolitis
}

\author{
Roopa Siddaiah*, Diane Kitch, Michael Davies, Harish Rao, Binu Sankoorikal, Pritish Mondal, E Scott \\ Halstead, Gavin Graff and Zissis C Chroneos \\ Department of Pediatrics, Penn State Health Milton S Hershey Medical Center, USA
}

*Corresponding author: Roopa Siddaiah, Assistant Professor, The Pennsylvania State University, College of Medicine, 500 University Drive, H085, Hershey, USA

\section{ARTICLE INFO}

Received: 湠 January 25, 2020

Published: 幽 February 06, 2020

Citation: Roopa Siddaiah, Diane Kitch, Michael Davies, Harish Rao, Binu Sankoorikal, Pritish Mondal, E Scott Halstead, Gavin Graf, Zissis C Chroneos. Safety and Yield of Exhaled Breath Condensate Analysis in Acutely Ill, Mechanically Ventilated Infants with RSV Bronchiolitis. Biomed J Sci \& Tech Res 25(3)-2020. BJSTR. MS.ID.004198.

\begin{abstract}
Exhaled breath condensate (EBC) analysis is a rapidly growing field of research and may be a useful non-invasive technique to evaluate lung pathology. There is little information in the literature on the safety of collecting these samples in acutely ill infants needing mechanical ventilation. Viral bronchiolitis is a common lower respiratory tract infection contributing to the majority of hospitalizations in children under 2 years of age. The pathophysiology of severe bronchiolitis resulting in ventilatory support is illdefined. Our study objective was to evaluate the tolerability of collection and utility of exhaled breath condensate (EBC) in molecular evaluation of viral bronchiolitis. We obtained proteomic profile of sequential EBCs over three days of illness from two infants who were intubated and ventilated. Mass spectrometry analysis of these samples identified cytokeratin at all time-points and time-dependent increase of proteins related to intracellular adhesions, epidermal morphogenesis, cell repair and differentiation that may be used to monitor the status of epithelial barrier function and integrity of intercellular communication in the bronchiolitis lung in the future. Our pilot study highlights that EBC collection is a well- tolerated procedure to obtain meaningful longitudinal data to profile and study the molecular parameters in acutely ill bronchiolitis infants.
\end{abstract}

Abbreviations: EBC: Exhaled breath condensate; RSV: Respiratory syncytial virus; IRB Institutional Review Board, AZGP1: Zinc Alpha 2 Glycoprotein; CASP14: Caspase 14; DCD: Dermcidin; ANXAA1: Annexins A1; ANXAA2: Annexins A2, C1orf68: Chromosome 1 Open Reading Frame 68 Protein of Unknown Function; CSTB: Cystatin B; DSC1: Desmocollin-1; DSG1: Desmoglein-1; FLG2: Filaggrin 2; GAPDH: Glyceraldehyde 3-Phosphate Dehydrogenase; JUP: Junction Plakoglobin, TGM3: Transglutaminase 3; UBA52: Ubiquitin-60s Ribosomal Protein L40

\section{Introduction}

Exhaled breath condensate (EBC) analysis is a rapidly growing field of research and may be a useful non-invasive technique to evaluate lung pathology. Several studies have used EBCs to detect inflammatory proteins and biomarkers in various lung pathologies including asthma, cystic fibrosis and Obstructive sleep apnea [1-3]. While this has been established as a promising tool in older children who are awake and can follow instructions to provide exhaled breath condensate, research is limited except for one study [4] that applied this technique to younger infants and those who are mechanically ventilated. In the present study, we report that EBC can be used to capture relevant molecular data representing the course of severe RSV bronchiolitis in hospitalized infants. Bronchiolitis is the most common cause of lower respiratory tract infection during the first year of life, and accounts for the majority of hospital admissions [57]. It is characterized by acute inflammation, edema and necrosis 
of epithelial cells lining small airways, increased mucus production and bronchospasm" [8].

Respiratory syncytial virus (RSV) is the most common cause of lower respiratory tract infections in young children, though other respiratory viruses can lead to a similar presentation [9]. Up to $3 \%$ of children with bronchiolitis are hospitalized and about
$1 \%$ of them require ICU admission, intubation and are at risk of death. Despite the high hospitalization rate for patients with bronchiolitis, controversy still exists regarding optimal treatment of these patients. The field lacks mechanistic evidence to advance therapeutic options [10-12]. The risk factors for otherwise healthy children who develop severe bronchiolitis requiring mechanical ventilatory support are ill defined.

\section{Methods}

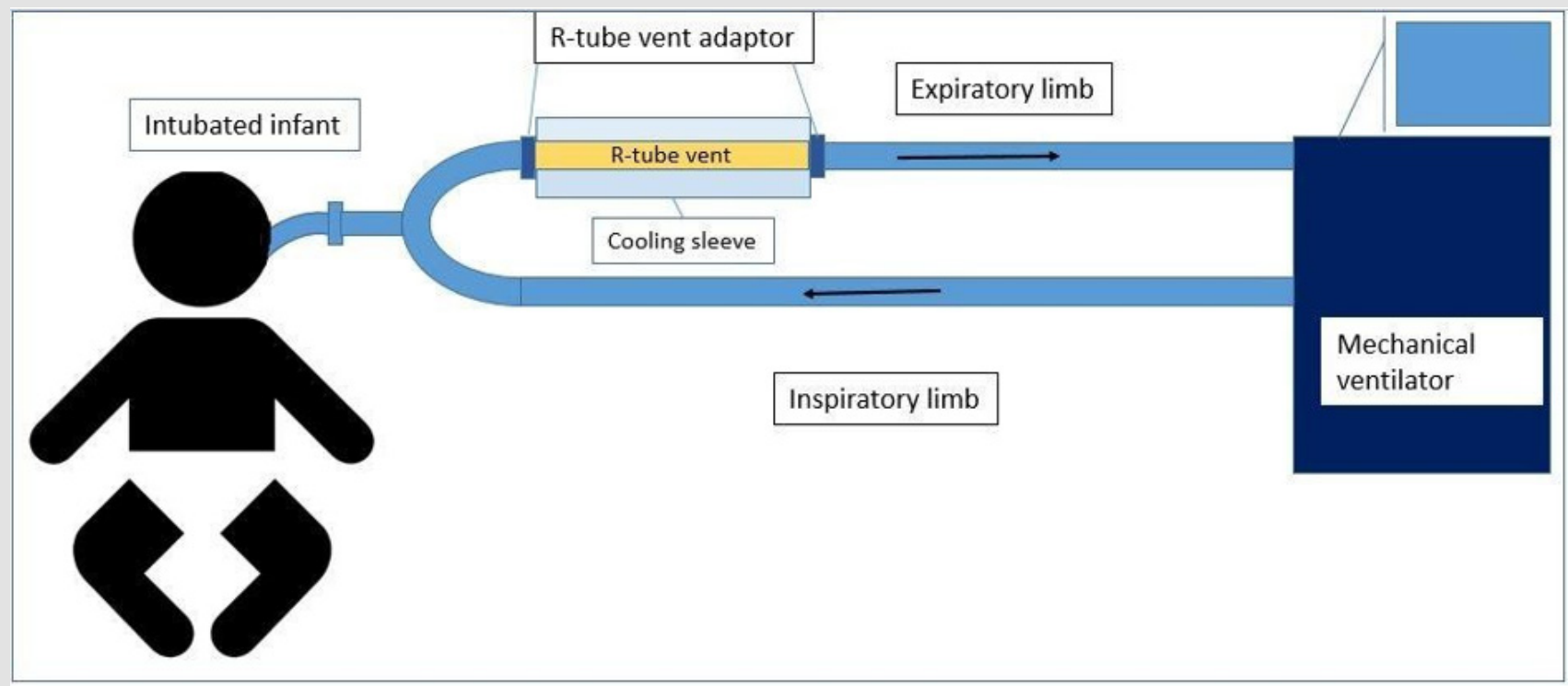

Figure 1: Ventilatory circuit showing valve-less $\mathrm{R}$ - tube vent placed in the expiratory limb, proximal to the patient to minimize dead - space.

The study was conducted in compliance with the protocol approved by the Penn State Hershey Children's Hospital Institutional Review Board (IRB) (PRAMS00042372), the relevant federal regulations, and IRB policies and procedures. Subjects were identified as infants with clinical diagnosis of acute severe bronchiolitis and who needed intubation and mechanical ventilation and informed consent was obtained from all participants included in the study. Children who were born preterm or experienced prior wheezing episodes, or had prior use of systemic or inhaled corticosteroids, were excluded from the study. EBC was collected in identified subjects within 24 hours of intubation and at 1 day intervals from that point forward until 3 samples were obtained from each subject. Samples were collected using an RTube VENT collection device consisting of valve-less tube structure with a cooling sleeve (Respiratory Research, Inc., Austin, TX) (Figure 1).

The RTube was connected to the expiratory limb of the ventilatory circuit proximal to the patient to limit the dead space proximal to sample collection by the trained study team. The vital signs and oxygen requirement and ventilator settings were documented by the study team before connecting the RTube and then the R-tube was connected for 15 minutes and then disconnected. Subjects were monitored by respiratory therapists who are oriented and trained throughout the time of sample collection and any significant changes in the patient parameters for during and after sample collection. Subject's oxygen requirement, ventilator settings and vital signs were recorded before and after each sample was collected. The breath condensate was then aspirated from the RTube and aliquoted immediately to be frozen at $-80^{\circ} \mathrm{C}$ until processing. For mass spectrometry, breath condensates were lyophilized overnight and re-suspended in $20 \mu \mathrm{L}$ MilliQ $\mathrm{H}_{2} \mathrm{O}$.

Proteins were denatured by $200 \mu \mathrm{L}$ 8M Urea in $0.1 \mathrm{M}$ Tris-HCL, pH 8.5 (urea solution) and trypsin digestion was performed by addition of $4 \mathrm{mg}$ trypsin in $75 \mu \mathrm{L}$ of $50 \mathrm{mM} \mathrm{NH}_{4} \mathrm{HCO}_{3}$ and incubated overnight at $48^{\circ} \mathrm{C}$. Peptides were fractionated by LC-MS/MS using an AB SciEX Triple TOF 5600 instrument. Peptide fingerprints were matched against the Swiss-Prot protein database using ProteinPilot 4.5 beta software.

\section{Results}

As a feasibility and safety study we collected 6 samples in total from 2 subjects ( 3 from each) at 24 hour intervals. Both subjects were less than one year of age ( 4 months and 8 months) and born at full term with no other known comorbidities such as premature birth, congenital malformations or previous history of asthma 
or use of inhaled or systemic steroids in the past. Both subjects were tested positive for respiratory syncytial virus on analysing their nasopharyngeal aspirates. Approximately $1 \mathrm{ml}$ of EBC in each sample was collected at each sample collection. The subjects tolerated the sample collection via the RTubes with no significant changes in pulse oximeter, supplemental oxygen requirement, heart rate, or respiratory rate during or after sample collection when compared to their baseline profile. Proteomic analysis of the EBC identified over 200 different proteins using Proteinpilot software.

Applying a stringent local false discovery rate (FDR) of $>2$, approximately 50 proteins (range 23-140) were confidently identified in each sample. Nine proteins, namely HRNR, KRT1, KRT4, KRT5, KRT9, KRT10, KRT14, KRT16, and KRT6A were consistently expressed in samples from both subjects and on all 3 days of sample collection. Expression of these proteins has been consistently documented in various inflammatory conditions such as atopic dermatitis and lung cancer [13-15]. We identified 5 proteins on both days 2 and 3 of intubation but not day 1, Namely Zinc Alpha 2 Glycoprotein (AZGP1), Caspase 14 (CASP14), Dermcidin (DCD), Desmoplakin (DSP), and Lysozyme (LYZ) which have been studied in immune regulation and cellular adhesion [16-18]. There were 12 proteins identified only in the day3 EBC sample in both subjects: Albumin (ALB), Annexins A1 and A2 (ANXA1, ANXA2), Chromosome 1 Open Reading Frame 68 Protein of Unknown Function (C1orf68), Cystatin B (CSTB), Desmocollin-1 (DSC1), Desmoglein-1 (DSG1), Filaggrin 2 (FLG2), Glyceraldehyde 3-Phosphate Dehydrogenase (GAPDH), Junction Plakoglobin (JUP), Transglutaminase 3 (TGM3), Galectin-7 (LGALS7/LGALS7B), and Ubiquitin-60s Ribosomal Protein L40 (UBA52) (Figure 2). These have been implicated in transcriptional signalling and ribosomal biogenesis $[19,20]$.

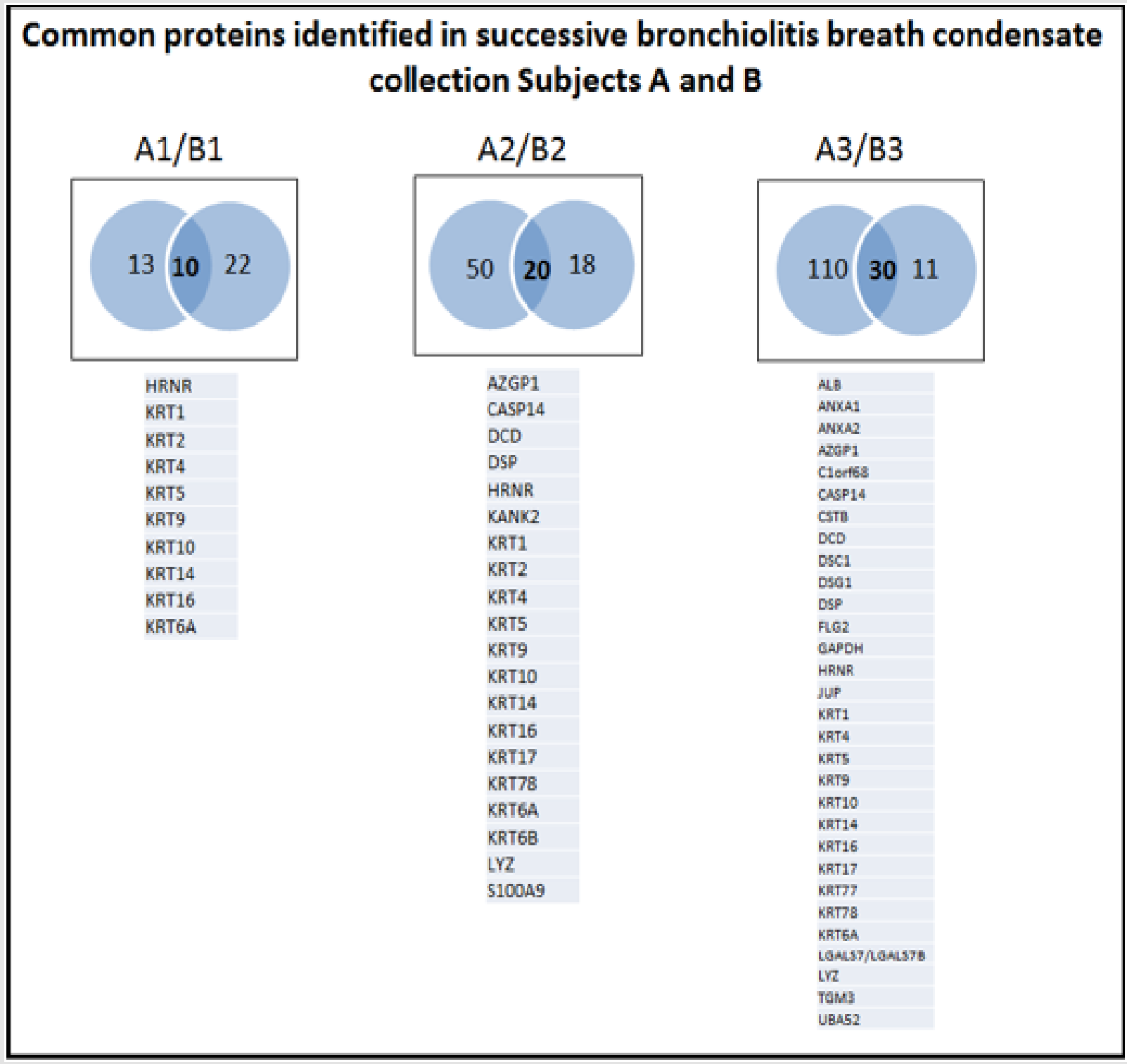

Figure 2: Sequential Venn diagram highlighting the common proteins expressed on Day 1, Day 2 and Day 3 of mechanical ventilation in severely ill bronchiolitis infants. 
Proteomic data sets from 3 consecutive days common to both subjects were analysed using the Database for Annotation, Visualization and Integrated Discovery (DAVID) for gene ontology term in order to identify biological processes during RSV infection. The top functional annotation systems in proteins isolated from day 1 samples suggested predominantly epithelial injury and the top functional annotation systems identified from day 2 suggested impairment of epithelial barrier function and intercellular communication. The top functional annotation systems from day 3 suggested that the main functional elements involve tissue repair and cell differentiation (Table 1) However given our small sample size we report this as a trend in pathophysiology.

Table 1: Demographic information on the two subjects and their cardiorespiratory parameters compared before and after exhaled breathe condensate collection.

\begin{tabular}{|c|c|c|c|}
\hline \multicolumn{4}{|c|}{ Demographic parameters } \\
\hline Age range in months & \multicolumn{3}{|c|}{ 4-8 months ( $\mathrm{n}=2)$} \\
\hline Gender (M: F) & \multicolumn{3}{|c|}{$1: 1$} \\
\hline \multirow[t]{2}{*}{ Race (Caucasian: African American) } & \multicolumn{3}{|c|}{$1: 1$} \\
\hline & Before & After & \\
\hline Fractional inspired Oxygen $\left(\mathrm{FiO}_{2}\right)$ requirement (mean value) & $0.3-0.45(0.366)$ & $0.3-0.45(0.366)$ & $(\mathrm{n}=6$ data points) \\
\hline Heart rate in beats per min (mean value) & $145-184(159.5)$ & $137-171(155.16)$ & $(n=6) p=0.33$ \\
\hline Respiratory rate in breaths per min (mean value) & $14-60(34)$ & $17-62(34.3)$ & $(n=6) p=0.96$ \\
\hline Oxygen saturation (mean value) & $98-100(99.19)$ & $98-100(98.83)$ & $(n=6) p=0.17$ \\
\hline
\end{tabular}

\section{Discussion}

EBC has been used as a non-invasive tool to evaluate lung lining fluid. However, its use has been limited in acutely ill pediatric patients due to the complexity of obtaining the samples. In our study we have demonstrated safe collection of EBC samples from intubated and mechanically ventilated infants with RSV bronchiolitis with no observed cardiorespiratory decompensation. We were able to collect sufficient quantity with good yield of protein in the sample to meaningfully evaluate the underlying lung pathology. Regarding RSV bronchiolitis therapy, there is limited evidence of role for steroids, nebulized epinephrine, helium oxygen or surfactant due to the lack of clear understanding of the underlying causes of the variation in clinical presentation. Our study seeks to evaluate the safety and yield of exhaled breath condensate sampling to analyse inflammatory proteins in acutely ill RSV infected infants. Evaluating serial samples in a time progression design in the same patient could be of value in determining the progression and trajectory of the disease and the readiness for extubation. Our findings offer support for a prospective study on a larger cohort of intubated and mechanically ventilated infants with bronchiolitis, to establish the underlying pathology and progression of the disease.

\section{Acknowledgements}

None of the authors have any competing interests in the manuscript. None of the authors have any financial benefits from product developers or manufacturers. This project was funded by Children's Miracle Network. The authors are grateful to Ms Rachael Mills for reviewing and editing the manuscript.

\section{References}

1. Carraro S, Baraldi E (2008) Exhaled breath condensate in children: present knowledge and future prospects. J Breath Res 2(3): 037003.
2. Caballero Balanza S, Martorell Aragones A, Cerda Mir JC, Belda Ramírez J, Navarro Iváñez R, et al. (2010) Leukotriene B4 and 8-isoprostane in exhaled breath condensate of children with episodic and persistent asthma. J Investig Allergol Clin Immunol 20(3): 237-243.

3. Malakasioti G, Alexopoulos E, Befani C, Tanou K, Varlami V, et al. (2012) Oxidative stress and inflammatory markers in the exhaled breath condensate of children with OSA. Sleep Breath 16(3): 703-708.

4. Hasan RA, Thomas J, Davidson B, Barnes J, Reddy R (2011) 8-Isoprostane in the exhaled breath condensate of children hospitalized for status asthmaticus. Pediatr Crit Care Med 12(1): e25-28.

5. Kyler KE, McCulloh RJ (2018) Current Concepts in the Evaluation and Management of Bronchiolitis. Infect Dis Clin North Am 32(1): 35-45.

6. Pelletier AJ, Mansbach JM, Camargo CA Jr (2006) Direct medical costs of bronchiolitis hospitalizations in the United States. Pediatrics 118(6): 2418-2423.

7. Ross E, Wiswell GB, Faulkner R, Macleod A, Handforth CP, et al. (1957) Epidemic bronchiolitis of infants; Nova Scotia 1956. Postgrad Med 22(1): 87-93.

8. (2006) American Academy of Pediatrics Subcommittee on Diagnosis and Management of Bronchiolitis. Diagnosis and management of bronchiolitis. Pediatrics 118(4): 1774-1793.

9. Piedimonte G, Perez MK (2014) Respiratory syncytial virus infection and bronchiolitis. Pediatr Rev 35(12): 519-530.

10. Mansbach JM, Pelletier AJ, Camargo CA Jr (2007) US outpatient office visits for bronchiolitis, 1993- 2004. Ambul Pediatr 7(4): 304-307.

11. Essouri S, Baudin F, Chevret L, Vincent M, Emeriaud G, et al. (2017) Variability of Care in Infants with Severe Bronchiolitis: Less-Invasive Respiratory Management Leads to Similar Outcomes. J Pediatr 188: 156162 e151.

12. Caballero MT, Polack FP, Stein RT (2017) Viral bronchiolitis in young infants: new perspectives for management and treatment. J Pediatr (Rio J) 93(Suppl 1): 75-83

13. Musah S, Chen J, Hoyle GW (2012) Repair of tracheal epithelium by basal cells after chlorine-induced injury. Respir Res 13: 107.

14. Lopez Sanchez LM, Jurado Gamez B, Feu Collado N, Valverde A, Cañas A, et al. (2017) Exhaled breath condensate biomarkers for the early 
diagnosis of lung cancer using proteomics. Am J Physiol Lung Cell Mol Physiol 313(4): L664-L676.

15. Henry J, Hsu CY, Haftek M, Nachat R, de Koning HD, et al. (2011) Hornerin is a component of the epidermal cornified cell envelopes. FASEB J 25(5): 1567-1576.

16. Vanni H, Kazeros A, Wang R, Harvey BG, Ferris B, et al. (2009) Cigarette smoking induces overexpression of a fat-depleting gene AZGP1 in the human. Chest 135(5): 1197-1208.

17. Liu J, Han H, Fan Z, El Beaino M, Fang Z, et al. (2018) AZGP1 inhibits soft tissue sarcoma cells invasion and migration. BMC Cancer 18(1): 89.

\section{ISSN: 2574-1241}

DOI: $10.26717 /$ BJSTR.2020.25.004198

Roopa Siddaiah. Biomed J Sci \& Tech Res

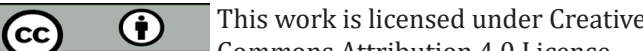

Submission Link: https://biomedres.us/submit-manuscript.php
18. Zhang AY, Grogan JS, Mahon KL, Rasiah K, Sved P, et al. (2017) A prospective multicentre phase III validation study of AZGP1 as a biomarker in localized prostate cancer. Ann Oncol 28(8): 1903-1909.

19. Arif A, Yao P, Terenzi F, Jia J, Ray PS, et al. (2018) The GAIT translational control system. Wiley Interdiscip Rev RNA 9(2).

20. Kobayashi M, Oshima S, Maeyashiki C, Nibe Y, Otsubo K, et al. (2016) The ubiquitin hybrid gene UBA52 regulates ubiquitination of ribosome and sustains embryonic development. Sci Rep 6: 36780.

BIOMEDICAL
RESEARCHES $\quad$\begin{tabular}{l} 
Assets of Publishing with us \\
\hline
\end{tabular}

